Maličević, Z., Lakić, Ž., Jugović, M., Mitrović, D. (2020): The significance of transversal distribution during the application of plant protection by boom sprayer. Agriculture and Forestry, 66 (3): 221-230.

DOI: 10.17707/AgricultForest.66.3.18

Zoran MALIČEVIĆ ${ }^{1}$, Željko LAKIĆ
Milan JUGOVIĆ

\title{
THE SIGNIFICANCE OF TRANSVERSAL DISTRIBUTION DURING THE APPLICATION OF PLANT PROTECTION BY BOOM SPRAYER
}

\section{SUMMARY}

The capacity of nozzles changes during the exploitation, i.e. it produces deviation from normal values. The consumption has an effect on the increase of the capacity of the nozzle, or the fraying and abrasion of the cartridge itself, which has a consequence of increased flow of the substance. On the other hand, decrease of the capacity occurs as a consequence of impurities which come with water which is used as a carrier of substances.

The aim of the study is to point to the significance of regular control of the nozzle capacity, since it affect on the quality of the application, all of which affect the deviation from the mean value of the transverse distribution.

Measured deviations of the nozzles according to the positions had significant deviations (5- decrease $83,33 \%$, or 13 - increase of the capacity for $61,11 \%$ ), and the consumption of the substance according to the surface (ha) fit perfectly. During designing and monitoring of the treatment standard, most of the producers monitor consumption (l/ha), and this paper points to frequent occurrences in practice (deviations) that can significantly affect the quality of the application, as shown by water-sensitive papers. The coverage of water-sensitive papers ranged from 5.60 to $57.40 \%$.

Keywords: nozzles, transversal distribution, boom sprayer, controlled application.

\section{INTRODUCTION}

In practice, it is often the case that manufacturers adjust the operating parameters (device capacity, operating speed) to achieve the desired norm in terms of consumption of the agent according to the treated area. Quality treatment, i.e. good transverse distribution implies uniform spray capacity as well

\footnotetext{
${ }^{1}$ Zoran Maličević (corresponding author: zoran.malicevic@agro.fabl.org), Faculty of Agriculture, University of Banja Luka, Republic of Srpska, BOSNIA AND HERZEGOVINA.

${ }^{2}$ Željko Lakić, Institute for Agriculture Banja Luka, Republic of Srpska, BOSNIA AND HERZEGOVINA.

${ }^{3}$ Milan Jugović, University of East Sarajevo, Faculty of Agriculture, Republic of Srpska, BOSNIA AND HERZEGOVINA.

${ }^{4}$ Dragoljub Mitrović, Biotechnical Faculty, University of Montenegro, MONTENEGRO.

Notes: The authors declare that they have no conflicts of interest. Authorship Form signed online.

Recieved:19/06/2020

Accepted:20/09/2020
} 
as good jet overlap. Change of the stated parameters occurs due to deviations from the nominal values of the capacity of individual sprayers on grains sprayers. Due to the deviation from the nominal values of the capacity, the quality application is disturbed through the uneven transverse distribution.

The mean value of the transverse distribution represents the mean volume value of the distributed liquid per treated area. A greater or lesser deviation from this mean represents the coefficient of variation. The coefficient of variation represents the numerical value of the distribution of fluid over the surface and allows the comparison of different results (Visacki, 2014).

The result of the treatment with damaged sprinklers is an uneven transverse distribution, and it reflects on the quality of the application despite the circumstances in terms of an ideal match of the tank consumption according to the treated surface. The cause of this phenomenon is the deviation of the sprayer from the nominal capacity. The result of increasing or decreasing the capacity of certain sprinklers is stated.

In order to achieve the most precise application of pesticides and complete crop protection, it is not enough that the sprayers have only a modern construction, but it is necessary that they have adequate exploitation potential (Djukic, 2008).

The exploitation potential of the sprayer represents the possibility for reliable execution of the set tasks, when applying pesticides. Exploitation potential implies quantitative and qualitative parameters.

Quantitative parameters include: pump capacity, sprayer capacity, hydraulic mixing device capacity, mutual harmonization of the stated capacities, gear ratio, tank volume, etc.

Qualitative parameters are: precision of dosing and capacity, uniformity of transverse distribution of pesticides, uniformity of droplets in the jet.

The precondition for a quality application is not the possession of a sprayer of a modern concept, but a well-adjusted sprayer that will provide a controlled application of pesticides, and thus the production of health-safe agricultural products. All of the above has influenced the fact that in the previous period, the control of the correctness of the sprayers became a regular obligation in most European countries (Sedlar, 2006). Inspections of sprayers are carried out in accordance with EN 13790. Belgium, Germany and the Netherlands are among the countries that were among the first to introduce mandatory inspections in accordance with this standard. In the area of northern Belgium in the period from September 1995 to December 1998, 17,466 sprayers were tested. Of the tested number of sprayers, 2,802 or $16 \%$ of sprayers did not pass the inspection, and therefore their exploitation potential was not satisfactory. Of the 2,802 sprayers, 2,409 (86\%) did not receive a quality certificate, due to worn nozzles or a faulty manometer (Langenakens and Pieters, 1999). Inspections of sprayers in Germany have shown that the cause of their malfunction in 19\% of cases are worn nozzles, then a faulty manometer and wing valves in $13 \%$ and $10 \%$ of cases, respectively (Rietz, 1998). At the second European symposium dedicated to the 
standardization of sprayer control procedures in Europe, held in Germany, a large number of authors point out the special importance of nozzles. Nozzles as the final elements of the sprayer determine the size of the droplets, the shape and angle of the outlet jet, the amount of liquid and the quality of coverage of the treated surface (Djukic, 2001).

The conducted inspections in the territory of Republika Srpska and Bosnia and Herzegovina also indicate the fact that the malfunction and poor exploitation potential are mostly affected by nozzles and faulty manometers (Malicevic, 2012). In $\mathrm{BiH}$ a significant problem is the practice of agricultural producers to buy parts of uncertain quality whose only advantage is the low price. A special risk is the choice of nozzles of questionable quality. Especially in such a situation, the positive effect of correctness control comes to the fore, and the aim of this paper is to point out the importance of quality control of nozzles, which are the most common cause of deviations in application. The use of watersensitive papers (WSP) is a fast and reliable method for assessing the quality of applications, which is the ultimate goal of the research.

\section{MATERIAL AND METHODS}

There are 60 different requirements that every plant protection machine must meet regarding inspections of sprayers in accordance with current standards and regulations. However, the most important thing is: pump operation control, manometer correctness control, mixer operation control and nozzle operation control.

Nozzles as key elements, i.e. their condition directly affect the quality of pesticide applications, i.e. the transverse distribution is in direct relation with the condition of the sprayers (Fig. 1). One of the basic parts is the nozzle cartridge that because of the high pressure exposure has its own lifespan, and is being withdrawn from service when it is worn out.

The service life of the sprayer depends on: the material of construction, the height of the pressure used, the condition of the filter and the maintenance.

The most efficient way to determine the condition of the sprayer is to permanently inspection, monitoring and comparing the flow rate of the old sprayer with the new one (same type and size).

Sprayer quality control involves control of the sprayer capacity and control of the transverse distribution of the sprayer (Sedlar, 2005). The "Laboratory for Testing and Calibration of Plant Protection Machines" has a sprayer capacity meter (Fig. 2), which was used in the research. It consists of an adapter for all types of sprinklers and a memory unit for storing 1000 data of measured capacities.

An Agromehanika AGS 440 mounted sprayer, aggregated with an IMT 539 tractor, was used in the experiment. The volume of the sprayer tank is 440 liters, and the working reach is $8 \mathrm{~m}$. Low pressure pump BM 65 from the same manufacturer, piston-membrane type (2 pistons) with a capacity of $65 \mathrm{l} / \mathrm{min}$ on $540 \mathrm{t} / \mathrm{min}$, serving 16 nozzles, with quality mixing. Nozzle carriers are 
monoconceptions and are equipped with universal flat-jet nozzles, with a working spray angle of $120^{\circ}$, red-marking coding, markings ID 90/120-04. Nozzles are marked so that looking at the nozzle in the direction of movement, the first on the left represents the number 1 , and the last on the right represents the nozzle no. 16 . The first eight nozzles treat the left side, while the nozzles at positions 9 - 16 treat the right side of the passage.

Pressures used to test the capacity were 3,4 and 5 bar providing a nominal capacity value of 1,$55 ; 1,80$ and $2,02 \mathrm{l} / \mathrm{min}$.

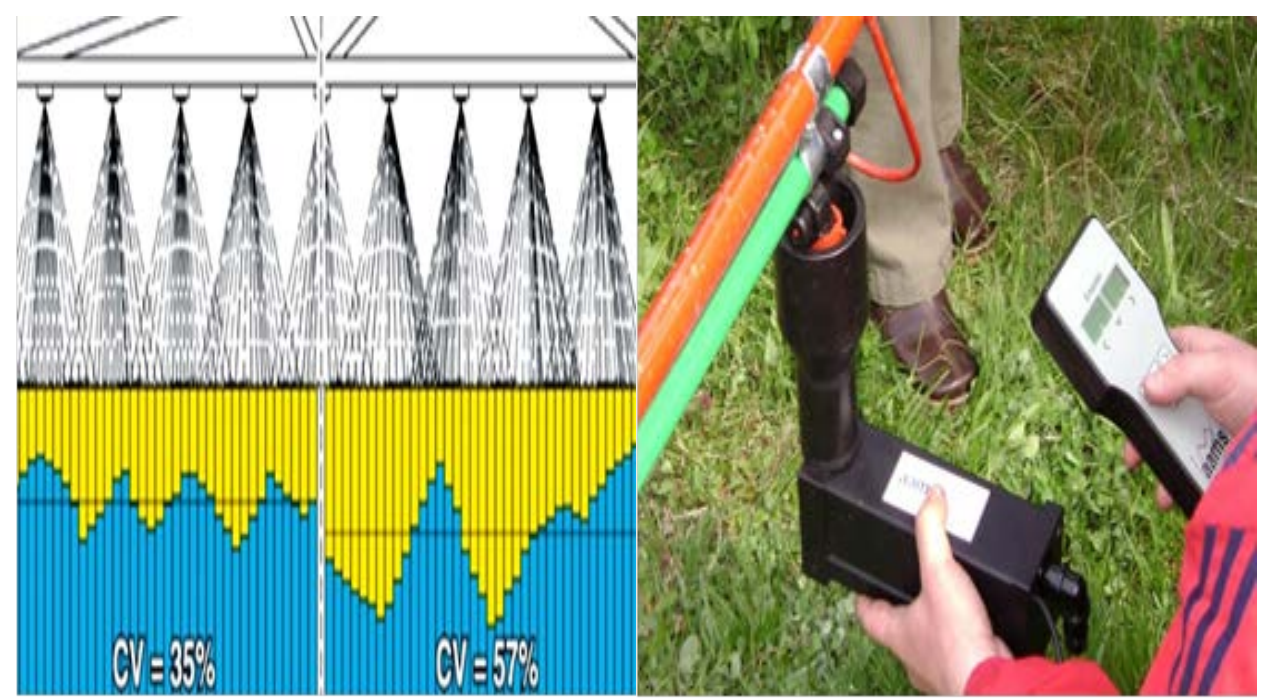

Figure 1. Deviation of transverse distribution

Figure 2. Capacity measurement (Photo: Malicevic Z.)

(Source: Internet: http: //www.lechler.de)

An Agromehanika AGS 440 mounted sprayer, aggregated with an IMT 539 tractor, was used in the experiment. The volume of the sprayer tank is 440 liters, and the working reach is $8 \mathrm{~m}$. Low pressure pump BM 65 from the same manufacturer, piston-membrane type (2 pistons) with a capacity of $65 \mathrm{l} / \mathrm{min}$ on $540 \mathrm{t} / \mathrm{min}$, serving 16 nozzles, with quality mixing. Nozzle carriers are monoconceptions and are equipped with universal flat-jet nozzles, with a working spray angle of $120^{\circ}$, red-marking coding, markings ID 90/120-04. Nozzles are marked so that looking at the nozzle in the direction of movement, the first on the left represents the number 1 , and the last on the right represents the nozzle no. 16. The first eight nozzles treat the left side, while the nozzles at positions 9 - 16 treat the right side of the passage.

Pressures used to test the capacity were 3,4 and 5 bar providing a nominal capacity value of 1,$55 ; 1,80$ and $2,02 \mathrm{l} / \mathrm{min}$.

Sprayer capacity testing included individual capacity measurement and comparison with nominal values. The quality of the application was monitored through the coverage of the WSP, which were set at 16 positions, following the 
positions of the sprinklers. The second part of the test included processing, analysis and display of realized capacities in all zones of the spray wing, i.e. deviation from nominal values (Table 1). WSP reading equipment includes the use of high-resolution scanners and processing in the program Image 1.44 , which involved determining the coverage of the treated area using appropriate algorithms.

Data on the coverage of plates and the number of drops was recorded on the basis of a passage, and was read using a program Image J 1.44. The program was developed by the U.S. National Institutes of Health, and is intended for professional analysis and processing of the photography. After collection and labeling, water-sensitive plates are scanned at high resolution, followed by loading and processing (Zhu, H. et al., 2011; Prodanov, D. Verstreken, K., 2012).

\section{RESULTS AND DISCUSSION}

Plant protection with technically right sprayer, and especially the condition of the nozzle, has a crucial influence on the quality of the application. Therefore, it is quite evident that this method of protection will be used also in the future what leads to the fact that pesticides should be used rational and all in order to decrease the quantity of chemical substances to be applied and the number of treatment. Researches in previous years have shown the opposite, frequent infections require a large number of treatments during the year, sometimes up to 20 times (Malicevic, 2010).

The service life, i.e. the period of exploitation of the nozzle, depends on the material of which the nozzle is made. Nozzle resistance to wear and tear represents service life. The nozzle should be withdrawn from operation as soon as the flow increases by $15 \%$ or more (GLOBALGAP). Working with nozzles that have flow increase of $15 \%$ and more than $15 \%$, represents loss both in terms of economy and quality of treatment and protection of the human environment (Djukic, 2008).

In practice, operators are in a dilemma when the sprayer should be withdrawn from use, i.e. when the flow has increased by more than $15 \%$. Due to all the above, nozzles 3,7 and 8 on the left side meet the condition to be withdrawn from operation due to increased flow. On the right side of the device, nozzles 11, 12, 13, 15 should also be withdrawn from service. Nozzles with reduced flow relative to nominal values should be cleaned and returned to service. The cause of the reduced capacity is mechanical impurities that can occur due to the use of poor quality water. There is a possibility of impurities in the preparation as well as sawdust due to friction of the working assemblies of the device.

There are two ways to reduce the possibility of exploiting nozzles that have exceeded the tolerance to increase the flow: The first way, is to control the nozzles after a certain time of use, e.g. 30 hours of operation. Another way is to purchase nozzles that have been tested by an authorized laboratory and that have 
the appropriate quality certificate from which it is clearly seen and after how many hours of operation the flow increases by $15 \%$.

Table 1. Sprayer capacity and deviations from nominal values

\begin{tabular}{|c|c|c|c|c|c|c|c|c|c|c|c|c|c|c|c|c|c|}
\hline \multirow{3}{*}{\begin{tabular}{||l|} 
\\
\end{tabular}} & \multirow{3}{*}{$\begin{array}{c}\mathrm{P} \\
(\text { bar })\end{array}$} & \multicolumn{16}{|c|}{ Nozzle position } \\
\hline & & \multicolumn{8}{|c|}{ Left side, capacity (l/min) } & \multicolumn{8}{|c|}{ Right side, capacity (l/min) } \\
\hline & & 1 & 2 & 3 & 4 & 5 & 6 & 7 & 8 & 9 & 10 & 11 & 12 & 13 & 14 & 15 & 16 \\
\hline \multirow{3}{*}{ 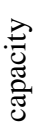 } & 3 & 1,29 & 0,34 & 2,06 & 1,55 & 0,26 & 0,43 & 2,06 & 1,89 & 1,12 & 1,29 & 2,41 & 2,41 & 2,49 & 1,46 & 2,23 & 1,20 \\
\hline & 4 & 1,50 & 0,40 & 2,40 & 1,80 & 0,30 & 0,50 & 2,40 & 2,20 & 1,30 & 1,50 & 2,80 & 2,80 & 2,90 & 1,70 & 2,60 & 1,40 \\
\hline & 5 & 1,68 & 0,45 & 2,69 & 2,02 & 0,34 & 0,56 & 2,69 & 2,47 & 1,46 & 1,68 & 3,15 & 3,14 & 3,25 & 1,91 & 2,92 & 1,57 \\
\hline \multirow{3}{*}{ 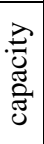 } & 3 & $-16,77$ & $-78,06$ & $+31,00$ & 0,00 & $-83,22$ & $-72,25$ & $+32,90$ & $+21,93$ & $-27,74$ & $-16,77$ & $+55,48$ & $+55,46$ & $+60,64$ & $-5,80$ & $+43,87$ & $-22,58$ \\
\hline & 4 & $-16,66$ & $-78,06$ & $+31,00$ & 0,00 & $-83,22$ & $-72,25$ & $+32,90$ & $+21,93$ & $-27,74$ & $-16,77$ & $+55,48$ & $+55,46$ & $+60,64$ & $-5,80$ & $+43,87$ & $-22,58$ \\
\hline & 5 & $-16,83$ & $-77,72$ & $+33,17$ & $0,00-$ & $-83,16$ & $-72,27$ & $+33,16$ & $+22,27$ & $-27,72$ & $-16,83$ & $+55,44$ & $+55,42$ & $+60,89$ & $-5,44$ & $+44,55$ & $-22,27$ \\
\hline \multirow{3}{*}{ : } & 3 & $-0,26$ & $-1,21$ & $+0,51$ & 0,00 & $-1,29$ & $-1,12$ & $+0,51$ & $+0,34$ & $-0,43$ & $-0,26$ & $+0,86$ & $+0,86$ & $+0,94$ & $-0,09$ & $+0,68$ & $-0,35$ \\
\hline & 4 & $-0,30$ & $-1,40$ & $+0,60$ & 0,00 - & $-1,50$ & $-1,30$ & $+0,60$ & $+0,40$ & $-0,50$ & $-0,30$ & $+1,00$ & $+1,00$ & $+1,10$ & $-0,10$ & $+0,80$ & $-0,40$ \\
\hline & 5 & $-0,34$ & $-1,57$ & $+0,67$ & 0,00 . & $-1,68$ & $-1,46$ & $+0,67$ & $+0,45$ & $-0,56$ & $-0,34$ & $+1,12$ & $+1,11$ & $+1,23$ & $|-0,11|$ & $+0,90$ & $-0,45$ \\
\hline \multirow{3}{*}{ 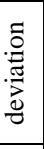 } & 3 & \multicolumn{8}{|c|}{$9,88(l / m i n)(-20,32 \%)$} & \multicolumn{8}{|c|}{$14,61(\mathrm{l} / \mathrm{min})(+17,82 \%)$} \\
\hline & 4 & \multicolumn{8}{|c|}{$11,50(\mathrm{l} / \mathrm{min})(-20,13 \%)$} & \multicolumn{8}{|c|}{$17,00(\mathrm{l} / \mathrm{min})(+18,05 \%)$} \\
\hline & 5 & \multicolumn{8}{|c|}{$12,90(\mathrm{l} / \mathrm{min})(-20,17 \%)$} & \multicolumn{8}{|c|}{$19,07(\mathrm{l} / \mathrm{min})(+18,00 \%)$} \\
\hline \multirow{3}{*}{ 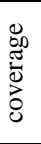 } & 3 & 26,6 & 10,5 & 49,7 & 37,8 & 5,60 & 13,3 & 53,2 & 41,3 & 14,7 & 23,8 & 51,8 & 53,9 & 57,4 & 30,1 & 39,9 & 20,3 \\
\hline & 4 & 25,8 & 12,3 & 52,1 & 32,2 & 8,4 & 23,1 & 57,2 & 25,3 & 18,5 & 33,6 & 57,1 & 56,6 & 54,5 & 40,2 & 31,1 & 25,6 \\
\hline & 5 & 31,2 & 26,8 & 41,1 & $19,8:$ & 32,2 & 39,5 & 49,4 & 19,8 & 28,9 & 42,7 & 50,2 & 49,3 & 56,8 & 45,6 & 39,5 & 33,2 \\
\hline \multirow{3}{*}{ 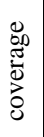 } & 3 & \multicolumn{8}{|c|}{$29,7(\%)$} & \multicolumn{8}{|c|}{$36,5(\%)$} \\
\hline & 4 & \multicolumn{8}{|c|}{$30,0(\%)$} & \multicolumn{8}{|c|}{ 39,8 (\%) } \\
\hline & 5 & \multicolumn{8}{|c|}{32,5 (\%) } & \multicolumn{8}{|c|}{$43,2(\%)$} \\
\hline
\end{tabular}

„,+“increase ; „,-“ decrease

Despite criticism of the excessive use of chemical plant protection products, farmers will continue to use and apply sprayers. If it is not possible to influence the use of chemicals to such an extent, the efficiency of the application can be increased through the control of transverse distribution. Good setting of the sprayer increases the quality and efficiency, which is manifested in better deposition of the agent and uniform application, and prevents inadequate and increased use of pesticides (Visacki, 2015).

The research aims to show that based on the presented parameters (total capacity of the device) the ideal usage of the agent per surface is obtained, while significant deviations from the aspect of nozzles flow are recorded, i.e. to indicate the importance of transverse distribution (Fig. 1). This can be the cause of problems with the application of pesticides, and is reflected in the fact that certain zones receive more funds, and others less. In the survey, only one nozzle meets the allowable deviation from the nominal flow value. 
Measured values of the sprayer capacity expressed in liters per minute are shown in table 1 . Values of measured capacities ( 3,4 and 5 bar) show significant deviations, both in the form of increase and decrease from the nominal value of capacity. In accordance with the current standards that regulate this area, which require withdrawal from operation in case of capacity increase by $15 \%$ and more, it is clear that seven nozzles do not meet the requirements of the standard. The table shows the quantities $(\mathrm{l} / \mathrm{min})$ as well as percentage deviations of the sprayer according to the positions, as well as deviations of the device capacity towards the sides. Positions of nozzles whose capacity exceeds the allowed deviation are: $3,7,8,11,12,13$ and 15 . Nozzles 3, 7 and 8 they are on the left side of the device while the others are on the right side of the device. The largest deviation of $60.89 \%$ in terms of capacity increase was recorded at the position of the nozzle number 13, which is located on the right side of the device. Nozzles at positions 11 and 12 also have an increased capacity of $55.46 \%$, which is high above the allowable deviation limit. The smallest deviation of $22.27 \%$ in terms of capacity increase was recorded at position 8 . The coefficient of variation is particularly high and ranged from $48,31 \%$ ( $\mathrm{p}=4$ bar) to $48,74 \%$ ( $\mathrm{p}=5$ bar), which can be considered very bad.

By concentrations in nuts, in most cases, the metals were arranged as the following diminishing series: $\mathrm{Fe}>\mathrm{Pb}>\mathrm{Zn}>\mathrm{Mn}>\mathrm{Cr}>\mathrm{Cd}$. Published data on the content of metals in nuts around the world are presented in Table 3.

The analysis of the obtained values of the tests shows a large deviation according to individual positions. In practice, this is a serious and common problem due to the fact that according to the form for calculating the standard, the average deviation is only $1.11 \%$, and the individual deviation by position is over $60 \%$. The analysis of the data from Table 1 measured the deviation towards the sides, which ranges from $17.82 \%$ in the form of an increase in capacity on the right, or a decrease in capacity of $20.32 \%$ on the left side of the device.

This is a common problem in which a large number of agricultural producers are found, i.e. as an indicator of the adjustment of operating parameters, they monitor the consumption of liquid according to the treated area, i.e. the consumption of preparations according to the sprayer tank. Deviation in the capacity of the nozzle is the cause of poor pesticide application, i.e. reflected in the uneven coverage of the treated area (fig. 3).

The average coverage at $\mathrm{p}=3$ bar was $33,10 \%$, at $\mathrm{p}=4$ bar was $34,91 \%$ and $37,83 \%$ at pressure of $p=5$ bar, which is the best result in research.

The coefficient of variation is also extremely high, and the best result can be considered $29.26 \%$ at a pressure of 5 bar, while at the other two pressures they are significantly worse.

Overcoming this problem lies in the fact that the control of the nozzle capacity eliminates the possibility of poor transverse distribution, reduces the coefficient of variation, and that the consumption according to the treated area fits perfectly. 


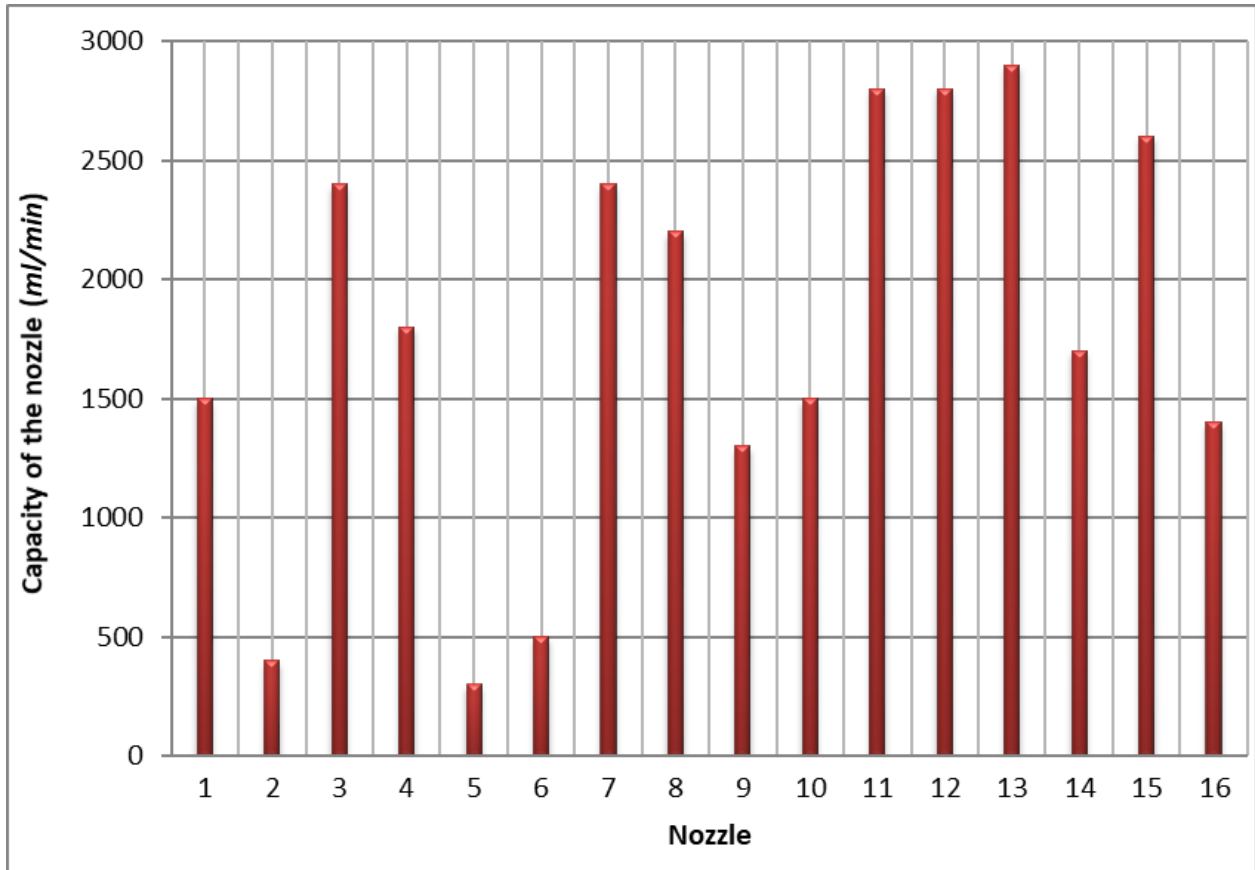

Graph 1. Capacity of inspected nozzles ( $\mathrm{p}=4$ bara)

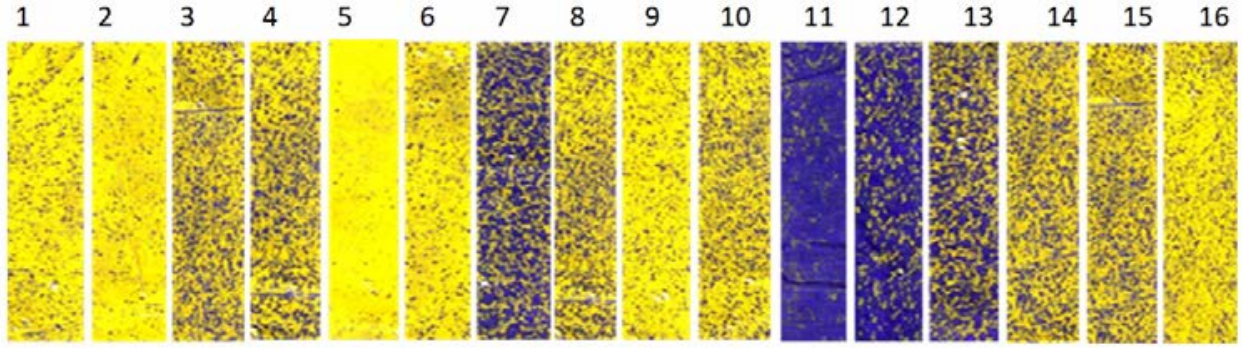

Figure 3. Coverage of water-sensitive papers ( $p=4$ bar)

(Photo: Malicevic Z.)

The control of the nozzle capacity provides a precondition for the controlled application of plant protection products, and the possibility of deviations in terms of capacity according to the positions of the nozzle is excluded.

\section{CONCLUSIONS}

The quality of application from the aspect of pesticide application devices cannot be characterized as satisfactory. A major problem in practice is the untrainedness of the operator of the application devices and the lack of basic knowledge in terms of adjusting the operating parameters that provide the norm of treatment. 
Treatment with inspected sprayer has multiple advantages over uncontrolled, and is reflected in: better uniformity in terms of transverse distribution, more uniform and better coverage of plant parts, lower usage of pesticides, increased performance of human and machine labor and lower cost of protection.

Inspection of the device, and especially the capacity of the nozzle, provides a model of controlled application of pesticides, which not only provides optimal consumption of pesticides but also improves the effect of transverse distribution. The tested capacity of the nozzle as well as the speed of movement enable the reduction of the norm and the dose of treatment, increases the precision of the device itself, and thus significantly increases the degree of protection of the human environment.

Nozzle capacity control is a reliable indicator of the quality of transverse distribution, and at the same time prevents the possibility of inaccurate application, with optimal consumption of the product according to the surface.

The conducted research and analysis indicate the necessity of regular control of the nozzle capacity, because the quality of the application largely depends on their condition.

Not enough attention is paid to the control of transverse distribution; however, these tests have shown that it is perhaps the most important segment in the quality and precise application of pesticides. Quality application implies control of transverse distribution, which is certainly a step towards optimizing the use of pesticides.

\section{REFERENCES}

Djukic, N., Sedlar, A., Bugarin, R. (2008): Defining a mathematical model of nozzle consuption and its significance for domestic production. Modern agricultural technology, 34, 1-2, 63-71.

Djukic, N., Sedlar, A. (2001): Good sprayer, effective protection. Review of agronomic knowledge, 6, 48-50.

Langenakens, J., Pieters M. (1999): Organization and Results of The Compulsory Inspection of Sprayers in Belgium. 7th International Congress on Agrcultural, Adana-Turkiye, 50-53.

Malicevic Z, Railic B, Mitric S, Babic M, Marceta I,. Improvement measures of the sprayers efficiency in order to apply small and medium norms by spraying orchards, Agroznanje, Banja Luka (2010), vol.11, br. 4., 135 - 140.

Malicevic, Z., Railic, B. Mitric, S., Mihajlovic, D., Babic, M. (2012): "Techniques for pesticide application in order to obtain GlobalGAP standards in the Republic of Srpska", Agroknowledge, vol. 13., br. 3., 421-430 str., Conference of agronomists of Republika Srpska.

Prodanov, D., Verstreken, K. (2012): Automated Segmentation and Morphometric of Cell and Tissue Structures. Selected Algorithms in ImageJ, In tech open sciens/open minds, Molecular Imaging, March 16th, 183 - 208. 
Rietz, S., Gamzlemeier, H. (1998): Inspection of plant protection equipment in Europe, AgEng, Oslo, 98-A-023.

Sedlar, A. (2006): Analysis of sprayer testing methods, Master's thesis, Novi Sad.

Sedlar, A., Djukic, N., Bugarin, R. (2005): The importance of regular sprayer inspection; Journal of Agronomic Knowledge, Novi Sad, br. 4

Visacki, V., Sedlar, A., Turan, J., Bugarin, R., Burg, P. (2014): Uniformity of pesticide application at the most common exploitation parameters. Modern agricultural technology, 40, No. 3, 125-134.

Visacki, V., Lazic, S., Sunjka, D., Sedlar, A., Bugarin, R., Turan, J., Burg, P. (2015): Determining the quality of application of field sprayer in corn, 41, No. 1, 57-66.

Zhu, H., Salyani, M., Fox, R.D. (2011): A portable scanning system for evaluation of spray deposit distribution, Computers and Electronics in Agriculture, 76: 38-43. 